\title{
IDENTIFIKASI PERMASALAHAN PADA KONTRUKSI JALAN, BANGUNAN PELENGKAP DAN FASILITAS PENDUKUNG JALAN STUDI KASUS JALAN DURI- PEKANBARU KM 30-31 KECAMATAN MINAS KABUPATEN SIAK
}

\author{
Fitridawati Soehardi; Fadrizal lubis;Lusi Dwi Putri \\ Program Studi Teknik Sipil Fakultas Teknik Universitas Lancang Kuning \\ Jl. Yos Sudarso Km. 8 Rumbai - Pekanbaru \\ Fitridawati_st@yahoo.co.id
}

\begin{abstract}
ABSTRAK
Ruas jalan Duri - Pekanbaru KM 30-31 merupakan ruas jalan nasional dengan kondisi geometrik yang mempunyai jalur yang menikung dan perkerasan jalan ini mulai mengalami kerusakan akibat beban lalu lintas sehingga pada ruas jalan ini mempunyai resiko rawan terjadi kecelakaan dan melintasi sekolah yang memiliki Zona Selamat Sekolah (ZoSS). Berdasarkan peraturan menteri pekerjaan umum no13 /PRT/M/2011 tentang Tata Cara Pemeliharaan dan Penilikan jalan. maka perlu dilakukan pemeliharaan secara rutin maupun berkala agar kerusakan kontruksi jalan beserta bangunan pelengkap dan fasilitas pendukungnya sejak dini. Tanggung jawab pembinaan jalan nasional berada pada pemerintah pusat (Direktorat Jenderal Bina Marga, Kementerian Pekerjaan Umum) dengan menggunakan dana APBN. Bertitik tolak pada kondisi tersebut maka dirasa perlu untuk mengidentifikasi permasalahan pada kontruksi jalan, bangunan pelengkap dan fasilitas pendukung lainnya pada ruas jalan Duri - Pekanbaru KM 30-31.

Penelitian ini dilaksanakan dengan melakukan pengumpulan data sekunder untuk memperoleh data penelitian menggunakan metode survey langsung, studi literature dan wawancara yang bertujuan untuk mengetahui permasalahan kontruksi jalan beserta bangunan pelengkap kontruksi jalan sepanjang Ruas jalan jalan Duri - Pekanbaru KM 30-31 dan solusi metode pemeliharaan dan perbaikan yang efektif dan efisien.

Hasil dari penelitian ini ditemukan bahwa terdapatnya kerusakan kontruksi jalan berupa lubang dan alur sebesar $0,8 \%$, hampir disepanjang jalan tersebut belum mempunyai drainase yang memadai dan drainase yang ada sebanyak $20 \%$ mengalami pendangkalan oleh tanah, sampah dan ditutupi oleh rerumputan, kondisi bahu jalan mengalami kerusakan sebesar 1,85\% akibat tergenangnya air dan banyaknya mobil bermuatan lebih yang sengaja parkir dibahu jalan. sebanyak 0,05\% rambu jalan mengalami kerusakan dan sebanyak 45\% Patok Pengarah dan rambu jalan tertutupi oleh rerumputan, dan kondisi marka ZoSS dan Marka jalan sebesar 17\% telah memudar.
\end{abstract}

Kata Kunci: Kerusakan Jalan, bangunan pelengkap, fasilitas pendukung.

\section{LATAR BELAKANG}

Jalan Nasional Merupakan jalan arteri dan jalan kolektor dalam Sistem Jaringan Jalan Primer. Ruas Jalan tersebut merupakan ruas Jalan Nasional yang sangat penting bagi kegiatan Perekonomi masyarakat dan menghubungkan antara Provinsi Riau dan Provinsi Sumatera Utara serta pelabuhan Dumai. Oleh karena itu tanggung jawab pembinaan jalan nasional berada pada pemerintah pusat (Direktorat Jenderal Bina Marga, Kementerian Pekerjaan Umum) dengan menggunakan dana APBN. Sehingga perlu dilakukan pemeliharan secara rutin demi meningkatkan kemampuan pelayanan dan meningkatkan kualitas jalan serta dapat melayani pertumbuhan ekonomi dan meningkatkan pendapatan masyarakat. 
Suatu kontruksi jalan dikatakan baik bila memiliki perkerasan yang kuat memikul beban lalu lintas di atasnya, dan mempunyai bangunan pelengkap serta fasilitas pendukung lainnya yang mempunyai fungsi masing -masing dalam mendukung kinerja kontruksi jalan tersebut. Untuk mendapatkan hasil kinerja yang optimal maka perlu dilakukan pemeliharaan jalan sesuai dengan peraturan Menteri Pekerjaan umum no 13/PRT/M/2011 Tentang Tata Cara Pemeliharaan dan Penilikan Jalan.

Berdasarkan hal tersebut, pengendalian dan pengawasan pemeliharaan jalan perlu dilakukan secara rutin maupun berkala agar kerusakan kontruksi jalan beserta bangunan pelengkap dan fasilitas pendukungnya sejak dini dapat dideteksi jenis dan volume serta cara penanganan, khususnya pada lokasi tertentu yang selalu terjadi kerusakan berulang. Pengendalian dan pengawasan pekerjaan pemeliharaan jalan menjadi penting dalam upaya meningkatkan kemampuan dan pengembangan jaringan jalan yang telah mantap guna melayani lalu lintas. Bertitik tolak pada kondisi mengetahui penanganan yang tepat untuk permasalahan pada kontruksi jalan beserta bangunan pelengkap dan fasilitas pendukung lainnya pada ruas jalan DuriPekanbaru Km 30-31 yang merupakan jalan nasional. Hal ini dikarenakan kondisi geometrik yang mempunyai jalur yang menikung dan perkerasan jalan yang mulai mengalami kerusakan akibat beban lalu lintas sehingga pada ruas jalan ini mempunyai resiko rawan terjadi kecelakaan dan melintasi sekolah yang memiliki Zona Selamat Sekolah (ZoSS). Berdasarkan hasil penelitian ini diharapkan dapat membanbatu pihak terkait dalam melakukan penanganan pemeliharan yang sesuai dengan kondisi ruas jalan ini.

\section{METODE PENELITIAN:}

Penelitian ini dilakukan pada ruas jalan Duri -Pekanbaru Km 30-31 Sepanjang $1 \mathrm{~km}$. Penelitian ini dilaksanakan dengan melakukan pengumpulan data sekunder berupa survey langsung kelapangan untuk memperoleh data penelitian berupa kondisi jenis kerusakan pada kontruksi jalan dan permasalahan pada bangunan pelengkap serta fasilitas pendukungnya.

\section{Cara Analisis data}

Data-data permasalahanpermasalahan pada kerusakan jalan dan bangunan pelengkap serta fasilitas pendukung kontruksi jalan yang didapat sesuai dengan kondisi real dilapangan kemudian dianalisis dengan cara mengelompokkannya sesuai dengan kategori kerusakan jalan sesuai dengan standar Binamarga. Berdasarkan hasil analisis data yang diperoleh dilakukan identifikasi masalah, kemudian mencari solusi perbaikan dan sistem pemeliharaan yang efisien sesuai dengan permasalahan dilapangan.

\section{HASIL DAN PEMBAHASAN}

Berdasarkan hasil pengamatan dilokasi pada Jalan Yos Sudarso Km 30 -31 Kecamatan Minas Kabupaten Siak yang dilakukan, maka dapat diidentifikasi beberapa permasalahan bangunan pelengkap dan fasilitas pendukung kontruksi jalan. Berdasarkan hasil pengamatan kontruksi jalan mengalami kemunduran dalam segi pelayanannya hal ini diakibatkan terdapatnya $0,8 \%$ kerusakan yang disebakan oleh alur dan berlubang, terutama Pada STA 30+150 dan STA 31+800 mulai mengalami pengelupasan agregat sehingga mengakibatkan timbulnya lubang-lubang pada kontruksi jalan dan pada STA $30+780$ terdapat alur. 


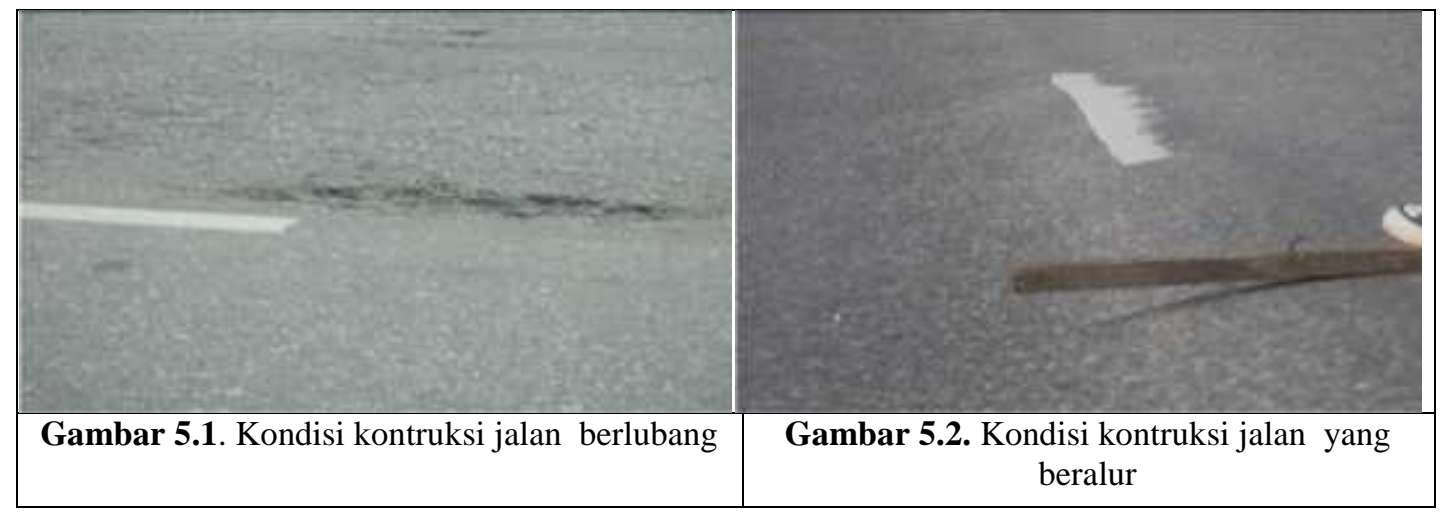

Hampir sepanjang jalan Pada STA 30+000 hingga STA 31+000 Sebanyak $80 \%$ kondisi dilapangan tidak memiliki saluran drainase yang memadai sehingga tidak ada kejelasan tentang penampungan air yang mengalir ketika hujan sehingga dapat

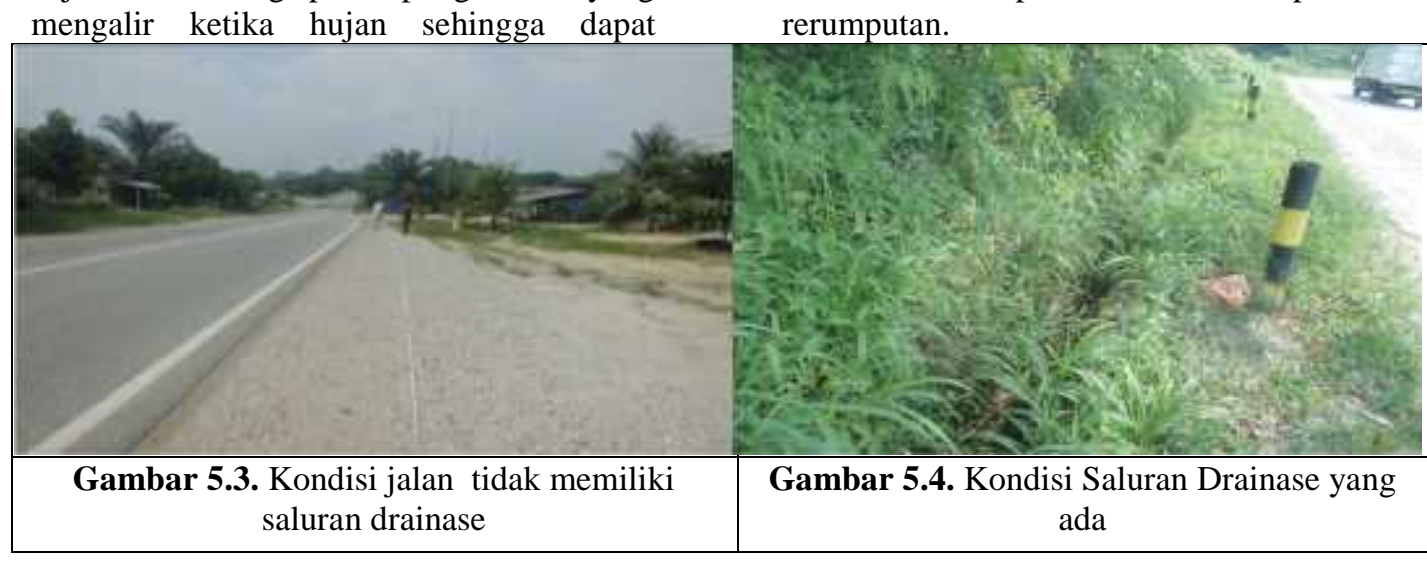

Berdasarkan pengamatan terdapat kerusakan sebanyak 1,85\% pada bagian bahu jalan. Hal ini di akibat tidak adanya saluran drainase yang memadai dan banyaknya kendaraan-kendaraan bermuatan banyak yang sengaja memarkirkan kendaraannya bagian bahu kiri dan kanan

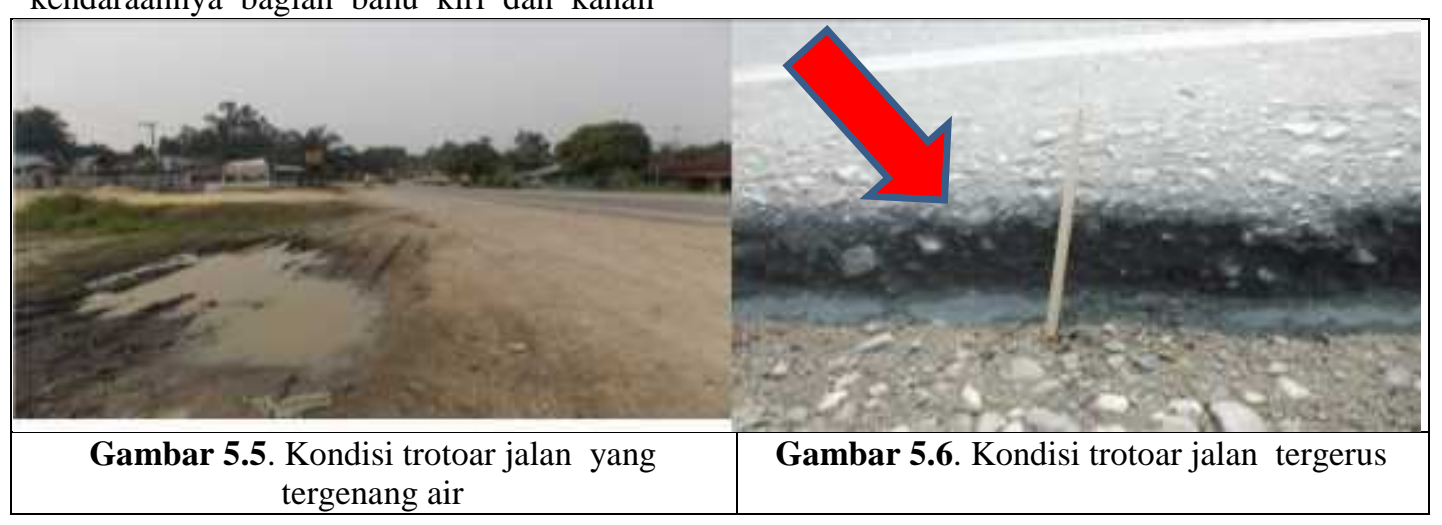

Hasil Pengamatan didapat sebanyak $0,05 \%$ terdapat kerusakan rambu mempengaruhi kondisi perkerasan jalan yg ada. Dan sebanyak $20 \%$ telah memiliki drainase yaitu pada STA $30+230$ dan STA 31+500 namun terdapat pendangkalan oleh tanah dan sampah serta di tutupi oleh rerumputan. 
tertutupi oleh tumbuhan yang cukup tinggi

dalam melihat rambu lalu lintas yang ada.

sehingga dapat mengganggu pengguna jalan

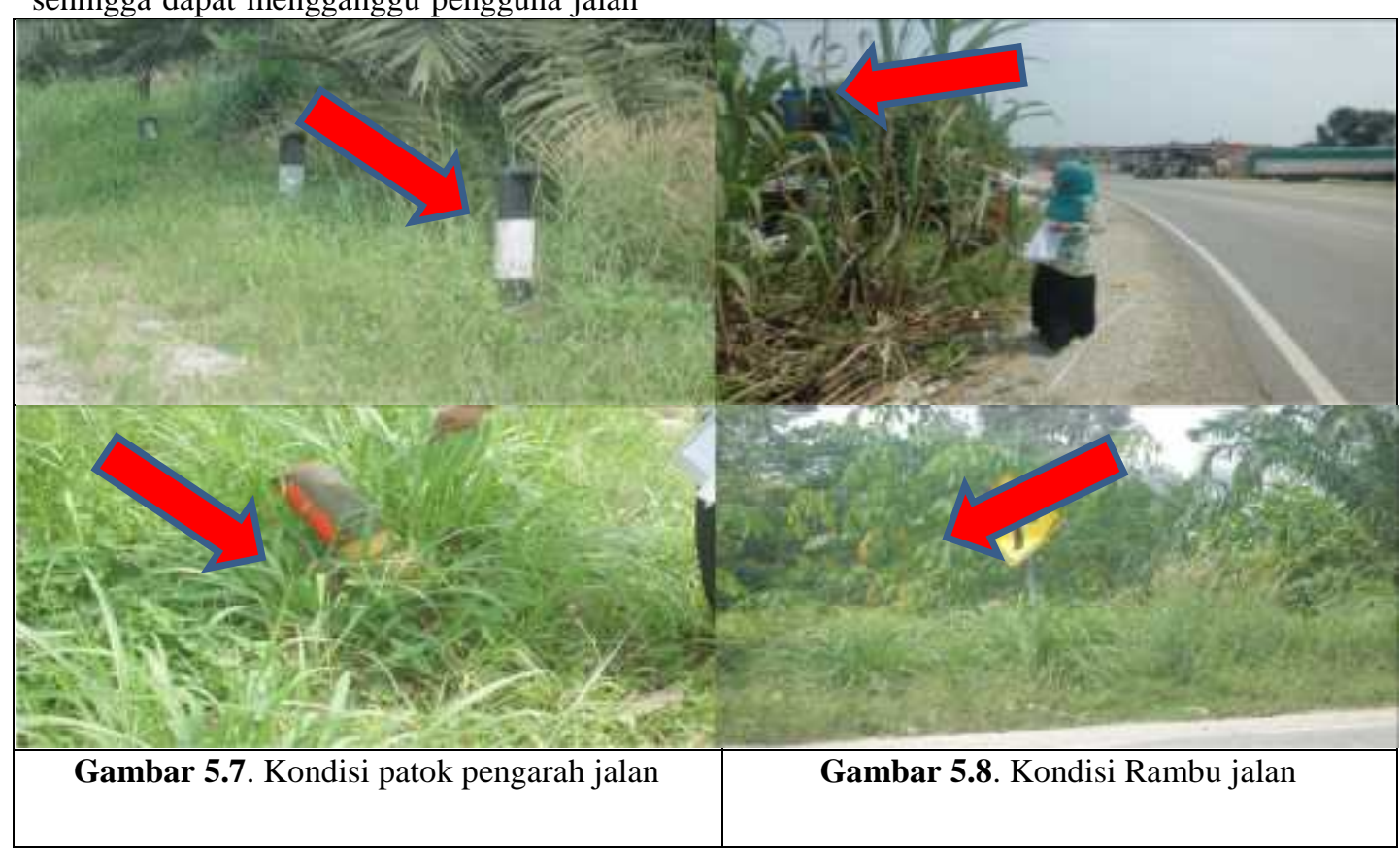

Pada STA 26+200 sampai STA 26+400 terjadi kerusakan sebanyak $17 \%$ dimana terdapat marka zona selamat sekolah (ZoSS) mulai memudar warnanya dan dibeberapa lokasi terdapat marka jalan yang mulai memudar. Hal ini dapat mengurangi kenyamanan bagi pengguna jalan.

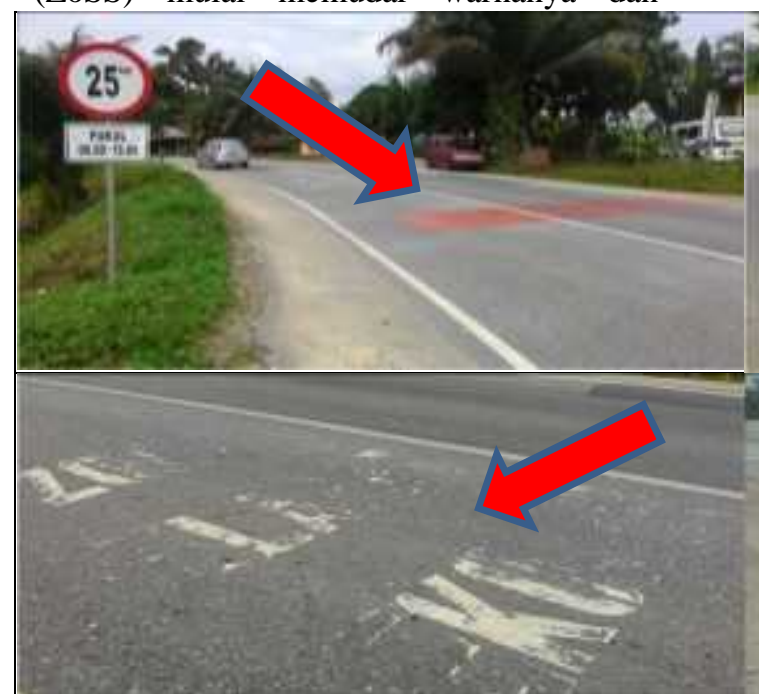

Gambar 5.9. Kondisi Marka ZoSS yang memudar

Sesuai hasil pengamatan di lapangan yang telah dilakukan sebelumnya maka perlu dilakukan penanganan lebih lanjut sesuai dengan permasalahannya sehingga dapat mengembalikan kondisi kontruksi jalan dan bangunan pelengkap serta fasilitas pendukungnya sesuai dengan

\section{kenyamana bagi pengguna jalan.}


air yang sesuai dengan kondisi dilapangan sehingga dapat berfungsi dengan baik.

Mengingat kondisi tanah pada trotoar cendrung miring dan lebih rendah dari kontruksi jalan yang ada, maka penulis mencoba untuk merencanakan saluran drainase yang sesuai. Perencanaan saluran drainase tersebut dapat terlihat pada gambar dibawah ini

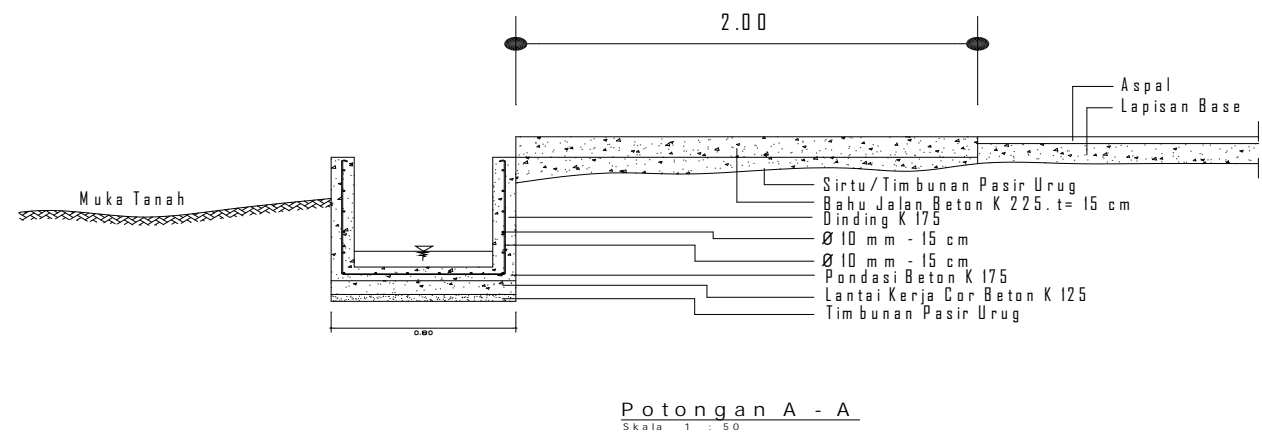

Gambar 1. Rencana Dimensi Saluran Drainase

Pada STA $30+230$ dan STA $30+500$ yang telah memiliki saluran drainase yang memadai namun akibat pendangkalan oleh tanah dan sampah serta ditumbuhi rerumputan, maka penangan yang harus dilakukan adalah dengan melakukan pemeliharaan secara rutin pembersihan saluran drainase sehingga air dapat mengalir dengan lancar kembali.

Hampir disepanjang jalan banyak terlihat kerusakan pada patok pengarah dan rambu jalan yang ada telah tertutupi oleh tumbuhan yang cukup tinggi sehingga dapat mengganggu pengguna jalan dalam melihat rambu lalulintas yang ada.

Pada STA $30+250$ terdapat marka zona selamat sekolah (ZoSS) mulai memudar warnanya dan dibeberapa lokasi terdapat marka jalan yang mulai memudar. Perlu dilakukan penanganan secara berkala dengan cara mencat ulang kembali pada bagian yang memudar.

Pada ruas jalan Duri - Pekanbaru Km 30-31 ini $\pm 80 \%$ saluran drainase yang ada tidak berfungsi sebagaimana mestinya, hal ini bisa sebabkan karena dimensinya yang kecil, bahan kontruksinya, bahkan dinding saluran drainase masih tanah, kemiringan dasar saluran. Pola kehidupan masyarakatnya yang masih suka membuang sampah sembarangan ke saluran drainase.. Tidak adanya koordinasi antar instansi terkait seperti PDAM, PLN dan Pihak Telkom dalam rangka penggalian
Pada STA $30+850$ terlihat bahwa rambu jalan yang ada telah tertutupi oleh tumbuhan yang cukup tinggi, penanganan yang dapat dilakukan adalah dengan memotong tumbuhan yang mengganggu rambu tersebut sehingga dapat membantu pengguna jalan dalam melihat rambu lalulintas yang ada.

dan pemasangan pipa atau kabel disamping badan jalan, sehingga terjadi penumpukan tanah pada saluran drainase, selesai pekerjaan tanpa ada pekerjaan tambahan untuk pembersihan atau pun merelokasi bahkan merenovasi saluran drainase yang terkena dampak pekerjaan tersebut.

\section{KESIMPULAN}

Dari hasil penelitian yang telah dilakukan, dapat ditarik beberapa kesimpulan sebagai barikut:

1. Berdasarkan hasil identifikasi permasalahan dilapangan ditemukan bahwa terdapatnya kerusakan kontruksi jalan berupa lubang dan alur sebesar 0,8 $\%$, hampir disepanjang jalan tersebut belum mempunyai drainase yang memadai dan drainase yang ada sebanyak $20 \%$ mengalami pendangkalan oleh tanah, sampah dan ditutupi oleh rerumputan, kondisi bahu jalan mengalami kerusakan sebesar 1,85\% akibat tergenangnya air dan banyaknya mobil bermuatan lebih yang sengaja 
parkir dibahu jalan. sebanyak $0,05 \%$ rambu jalan mengalami kerusakan dan sebanyak 45\% Patok Pengarah dan rambu jalan tertutupi oleh rerumputan, dan kondisi marka ZoSS dan Marka jalan sebesar $17 \%$ telah memudar.

2. Penanganan yang dilakukan adalah dengan melakukan pemeliharaan rutin untuk membersihkan saluran drainase dan pemangkasan rerumputan yang menutupi saluran drainase, patok pengarah jalan dan rambu lalulintas yang ada. Sehingga dapat mengembalikan fungsinya menjadi lebih baik. Dan untuk kerusakan pada kontruksi jalan berupa alur dan lobang perlu dilakukan pemeliharan berkala dengan melakukan penambalan atau pelapisan ulang, sedangkan patok pengarah dan rambu jalan perlu dilakukan penggantian dan untuk marka perlu dilakukan pengecetan ulang.

\section{SARAN}

Saran atau langkah yang dapat dilakukan untuk kerusakan saluran drainase di jalan ruas jalan Yos Sudarso STA $30+000$ hingga STA $31+000$ adalah :

1. Adanya peran serta aktif pemerintah dalam menangani permasalahan yang ada dengan melakukannya perawatan rutin dan berkala yang terjadwal pada kontruksi jalan dan bangunan pelengkap serta fasilitas pendukungnya sehingga dapat berfungsi dengan baik dan dapat bermanfaatkan bagi pengguna jalan.

2. Adanya koordinasi antar pihak-pihak terkait dalam pelaksanaan pemeliharaan kontruksi jalan dan bangunan pelengkap serta fasilitas pendukungnya misalnya Telkom, Pln, dll.

3. Perlu adanya perencanaan ulang terhadap sistem drainase yang ada.

\section{DAFTAR PUSTAKA}

Direktorat Jenderal Bina Marga, 1990. Tata Cara Penyusunan Program Pemeliharaan Jalan Kota, No. 018/T/BNK/1990

Direktorat Jendral Bina Marga, 1995. Metode Survei, Buku Manual Pemeliharaan Rutin untuk Jalan Nasional dan Jalan Propinsi, No.002/T/Bt/1995, Departemen Pekerjaan Umum, Direktorat Jendral Bina Marga, Jakarta

Direktorat Jendral Binamarga, 2011Perbaikan Standar untuk Pemeliharaan Rutin. Buku Manual Kontruksi dan Bangunan, No.001-002/M/BM/2011, Kementrian Pekerjaan Umum Direktorat Jendral Binamarga, Jakarta.

Hardiyatmo,H.C, 2009. Pemeliharaan Jalan Raya, Gajah Mada University Press, Yogyakarta

Peraturan Menteri Perhubungan Republik Indonesia Nomor PM 13 Tahun 2014 tentang Rambu Lalu Lintas

Peraturan Menteri Perhubungan Republik Indonesia Nomor PM 34 Tahun 2014 tentang Marka Jalan

Sukirman. S (1999). Perkerasan Lentur Jalan Raya, Erlangga, Jakarta

Syapawi, Ahmad, 2013, “Studi Permasalahan Drainase Jalan (Saluran Samping) dilokasi Jalan Demang Lebar Daun Sepanjang \pm 3900 m (Lingkaran SMA Negeri 10 s.d Simpang Polda)”, PILAR Jurnal Teknik Sipil, Volume 9,No.2, September 2013 